\title{
Peer-to-Peer Social Media as an Effective Prevention Strategy: Quasi-Experimental Evaluation
}

William Evans ${ }^{1}$, PhD; Elizabeth Andrade ${ }^{1}$, DrPH; Michaela Pratt ${ }^{2}$, BA; Alexandra Mottern², MS; Sergio Chavez ${ }^{2}$, BA; Anthony Calzetta-Raymond ${ }^{1}$, BA; Jiayan $\mathrm{Gu}^{1}$, MS

${ }^{1}$ Milken Institute School of Public Health, George Washington University, Washington, DC, United States

${ }^{2}$ Mentor Foundation USA, Tysons, VA, United States

Corresponding Author:

William Evans, $\mathrm{PhD}$

Milken Institute School of Public Health

George Washington University

Washington, DC

United States

Phone: 12023519546

Email:wdevans@gwu.edu

\section{Abstract}

Background: Substance use by adolescents remains to be at unacceptably high levels, and there is evidence that teens' social norms are becoming more favorable toward recreational use and perceived safety of substances such as marijuana and prescription opioids. Social media offer a low-cost, potentially high-impact approach to disseminate prevention messages.

Objective: Living the Example (LTE) is a program that trains adolescent youth ambassadors to develop and disseminate prevention messages within their own social media networks and through in-school activities. This study aimed to evaluate the effects of exposure to LTE-based social media on students in the youth ambassadors' networks.

Methods: The George Washington (GW) University designed and implemented a quasi-experimental evaluation of the LTE program in 3 Maryland high schools. Before program launch, a sample of 826 students (wave 1) at the 3 schools, drawn from a census of freshmen enrolled in a class attended by all students at the grade level, completed a survey. A total of 584 students were surveyed at the wave 2 program midpoint and 542 at the wave 3 endpoint. The survey contained questions on drug use-related attitudes, beliefs, intentions, and behaviors, all based on validated measures. We evaluated the effects of LTE on the intended next 30-day drug use, and controlling for LTE self-reported exposure, age, and gender from waves 2 and 3 was appended into a single dataset. We first conducted ordinal logistic regressions for each drug use intention in wave 3 (ie, sell or distribute illegal drugs, smoke cigarettes, drink beer/wine/hard liquor when parents do not know about it, use marijuana, use lysergic acid diethylamide, cocaine, amphetamines or other illegal drugs, use heroin, use synthetic drugs, and use any prescription pills without a prescription) to examine the association between LTE exposure and drug use intentions. We included an interaction term for the study wave to examine intervention effects.

Results: We found a significant positive effect of LTE exposure on all 8 measured drug use intentions: sell/distribute illegal drugs; smoke cigarettes; drink beer, wine, or liquor when my parents do not know about it; use marijuana; use cocaine, amphetamines, or other illegal drug; use heroin; use synthetic drugs; use any prescription pills without a prescription (all $P<.05$; odds ratios ranging from 2.12 to 3.71 ). We also found that boys were more likely than girls to exhibit reduced drug use intentions. We also found reductions in 30-day intentions between the second and third survey waves for all 8 measured drug use variables.

Conclusions: Overall, the results are consistent with and indicate a stronger LTE effect in this study compared with a previous pilot study. LTE appears to offer a protective effect, with exposure to program messages leading to reduced/improved drug use intentions.

(JMIR Mhealth Uhealth 2020;8(5):e16207) doi: 10.2196/16207

\section{KEYWORDS}

social media; substance use; prevention; marijuana; opioids; adolescent health 


\section{Introduction}

\section{Background}

As shown in the most recent Monitoring the Future study, substance abuse is among the greatest public health threats [1] Substance use by adolescents remains to be at unacceptably high levels, and there is evidence that teens' social norms are becoming more favorable toward recreational use and perceived relative safety of substances such as marijuana and prescription opioids [2-4]. Teens are particularly sensitive to the messaging about drugs in their social environment, including in digital communities, and drug use choices are driven by availability, acceptability, and perceived risk [5,6]. Recently there have been many changes in the availability of marijuana to the public. The consequences of use and the situations in which individuals may choose to use marijuana are changing in many states owing to medical marijuana and legalization [7], potentially influencing youth perceptions of acceptability and risk [8]. Furthermore, due to widespread availability and a landscape of more dangerous drugs, including fentanyl contamination, opioid overdose death rates continue to rise despite overall declines in use [9,10]. Yet, some US $\$ 40$ billion per year is spent on prevention programs [11], including major efforts involving health communication, such as the Above the Influence campaign [12]. Given this growing public health threat, prevention efforts must prioritize engagement strategies that address the evolving substance use risk perceptions and leverage youths' and young adults' affinity for digital technology [13].

There is growing evidence that marijuana use has negative health consequences for adolescents, especially when use begins early and when combined with other substance use [14]. Recent studies suggest adolescent marijuana use may be linked to altered longer-term neurodevelopmental trajectories and compromised neural health, impaired frontal lobe function, and psychosocial effects [14-16]. Additionally, early-onset adolescent marijuana use combined with alcohol and other substance use has been linked to numerous cognitive impairments and neural health effects $[17,18]$. Social norms favoring marijuana use are increasing $[19,20]$ and may be associated with the relaxation of marijuana laws [21,22]. At the same time, both natural and synthetic opioid use has clear and well-documented health consequences, and adolescents are at a heightened risk for long-term neurodevelopmental effects [23]. Approximately $68 \%$ of the 70,237 drug overdose deaths in 2017 involved opioids, and over 28,466 of those deaths were from synthetic opioids such as fentanyl [24].

\section{Social Media and Prevention}

Social media and social networks are major drivers of public debate and perceptions of marijuana, opioids, and other drugs $[7,14,15,25,26]$, including for the youth, and there are numerous messages promoting the acceptability of substance use in these digital networks. This highlights the need for novel interventions that use digital prevention strategies and offer a counternarrative or counterargument [27]. Recent studies have examined exposure to antidrug communications and found that counternarrative strategies may partially explain positive campaign outcomes [28,29]. A campaign's brand marketing strategy may in part determine how the audience responds to antidrug advertising [12]. Substance abuse prevention programs and behaviors promoted by these programs can have brand identities as well. Recent studies have linked drug resistance branding to improved substance use outcomes [30,31]. Our research team has pioneered branding for prevention in multiple domains [32,33]. In the context of relaxed marijuana laws and heightened opioid risk, this study investigated how prevention can be optimized through branded peer-to-peer messaging and digital engagement.

The Mentor Foundation USA implements a program entitled, Shatter the Myths (STM) Youth Rallies-this program conducts interactive in-person events with high school students and is designed to raise an awareness of risks and dispel myths surrounding drug use [34-37]. STM Youth Rallies are based on recent neuroscience, use an experiential learning approach to prevention, and apply principles from branding and social marketing $[38,39]$. By focusing on youths' innate talents and strengths, the rallies enable youths to become advocates regarding the benefits of living a drug-free lifestyle.

Mentor Foundation USA is part of the Mentor International organization, which implements youth development programs worldwide. Mentor International's work is guided by the Positive Youth Development (PYD) theory [40], working with children and families to combat risk behaviors and promote healthy lifestyles. Mentor International follows the United Nations Sustainable Development Goals, in particular, by ensuring healthy lives and promoting well-being for all ages.

Living the Example (LTE) has been designed based on the PYD theory, following the authors' previous research, to address the rapidly changing substance use social environment in the United States by empowering the youth to serve as peer change agents $[41,42]$. LTE builds upon the STM Youth Rallies by adding a social media-delivered component to spread peer-to-peer substance use prevention messages, while also applying social marketing and branding approaches.

LTE represents a novel approach to addressing a wide range of substances used by adolescents through gain-framed messaging and digital engagement. According to the Prospect Theory, framing warnings to emphasize the negative health effects of marijuana and opioid use (ie, loss-framed) or benefits of avoiding marijuana and opioid use (ie, gain-framed) will differentially affect prevention outcomes $[43,44]$. Research on message framing [45-47] and prevention messages for preteens and teenagers [48-50] suggests that gain-framed messages may be effective. Specifically, research on smoking cessation messaging favors gain-framed messages about prevention and health-promoting behaviors [51-53]. For example, the communication theory indicates that gain-framed messages conveying the health benefits of quitting smoking may be optimal to promote cessation [54]. Such messages have the potential to produce behavior change through mediated pathways, such as enhancing beliefs that quitting reduces risks and reducing the attractiveness of industry branding [55,56]. Similar gain-framed messages can be adapted to marijuana and opioid use prevention to address the changing prevention environment. The use of graphic imagery has also been found 
to contribute to the uptake of gain-framed health messages [57,58]. Social media are effective tools to share graphic, multimedia prevention content that may enhance framing effects. LTE is promising in that it applies this approach to prevention by promoting the use of positive antidrug brand representations delivered via peer networks on social media.

\section{Living the Example Intervention Research}

In this study, we adapted and evaluated a novel intervention, LTE, which has been previously pilot tested and demonstrated to be effective in reducing 30-day marijuana and prescription painkiller use intentions [42]. The LTE pilot was based on an after-school curriculum for youth ambassadors, followed by ambassador promotion of peer substance use avoidance with user-generated content via digital social networks and through school-wide change projects. LTE addresses numerous forms of substance use overall, including all widely used illicit drugs and alcohol, and the evaluation includes measures of intentions and use. This study focused specifically on marijuana and opioid use due to the rapid growth and prevalence of these substances and because the previous pilot demonstrated effectiveness in reducing use intentions.

The specific aim of this research was to implement and evaluate the adapted LTE curriculum in 3 suburban Maryland high schools. We tested 3 hypotheses:

1. LTE youth ambassador training would be successful in disseminating prevention messages via social media during the school year.

2. Exposure to LTE would be associated with lower 30-day substance use intentions at follow-up.

3. Higher levels of exposure to LTE would be associated with a reduction in 30-day substance use intentions across the program implementation period.

\section{Methods}

\section{Design}

We employed a quasi-experimental design (QED) through 3 cross-sectional surveys of freshmen at each school to test dose-response effects of exposure to LTE social media and school-based activities on substance use outcomes. We collected self-reported data on outcomes through questionnaires administered at 3 waves before, during, and at the conclusion of the program in the 3 high schools over a period of 9 months. We also collected data from the social media platforms used by students, such as Instagram, to independently measure their LTE posting activity.

\section{Intervention}

The LTE curriculum was delivered as a series of structured after-school group sessions of 90-min each, 1 session per week. The sessions were delivered by a single program staff member following this outline:

- Session 1: What is a brand? Describe the idea of branding and branding substance use prevention.

- Session 2: Introduction to social media. Learn basics of social media, how it can influence message recipients, and how to create influential messages.
- Session 3: Boosting online engagement. How to connect and build engagement with social networks.

- Session 4: Using your voice-introduction to advocacy. Learn how to share opinions about an issue in the community with aim of influencing peers.

- Session 5: Advocacy in action. Develop skills to advocate for substance use prevention with peers.

- Session 6: Applying what we have learned. Ambassadors develop live content, share it with their social media networks, and engage with their peers.

Program staff, who were counselors and other school officials, recruited youth ambassadors at the 3 schools (46 in total), all seniors, at the start of the school year. The LTE curriculum sessions were then delivered through in-school sessions with ambassadors at school-assigned times. Each session was followed by staff-led questions and discussion topics to ensure ambassador comprehension of the content.

Following the last session, ambassadors were given 2 weeks to develop prevention content and share it live with their social media networks. This represented the launch of LTE prevention messaging to the broader student population beyond the ambassador group. After the initial ambassador training and launch of peer-to-peer prevention messaging, the program staff maintained weekly in-person, SMS text message, email, and instant messaging contact with ambassadors to encourage regular social media posting and provide help and encouragement in a coaching function. Additional activities, projects, and competitions were scheduled to keep youth ambassadors engaged in the LTE program throughout the course of the academic year. Competitions offered opportunities for youths to compete against each other and win prizes for their social media content and peer outreach. This strategy rewarded ambassadors for creative outreach techniques, effective inclusion of prevention content, persuasive and engaging tactics, compelling narrative stories, and other noteworthy features of their work. These competitions were also intended to boost intervention reach and amplify prevention messaging-for example, prizes were awarded for generating the most social media engagement (ie, shares, reactions, or comments) and using the \#livingtheexample hashtag.

After completing the initial 6-week training curriculum, each participating school submitted a project description and budget to receive a monetary stipend to complete a "change project." Youth ambassadors were challenged to design and implement change projects to increase peer knowledge and awareness about the harmful effects of substance use and address social norms, stigma, and perceptions about substance use and addiction. Approved and funded projects were implemented during the spring semester. Following successful project completion, each school submitted results of their work in the form of photos/videos and reports. These change projects were part of the overall LTE intervention and were captured in social media posts by youth ambassadors; measures of LTE exposure are inclusive of this activity.

In the spring of 2019, the program staff led interactive STM substance use prevention youth rallies at each participating school. Large numbers of students attended each rally, which 
were held as school-wide assemblies. We do not have data on exact attendance. The purpose was to draw attention to the overall substance use prevention program, generate enthusiasm surrounding the youth ambassadors, and stimulate interest in ambassador LTE social media posts. We note that this was a 1-time event and served to reinforce the ongoing program. The STM rally was designed to dispel marijuana and opioid use myths (ie, that most peers use marijuana or that opioid use is safe) and to encourage positive peer influence. The STM rally focused on youths' talents and strengths, enabling them to become prevention advocates. The STM rally featured thought-provoking speakers, including youth ambassadors, a scientist from the National Institute on Drug Abuse (NIDA) who educated students about the science behind substance use and the adolescent brain, and a young person in recovery sharing an honest testimonial.

\section{Measures and Instruments}

We adapted a previously tested questionnaire using validated scales from previous work by the authors $[59,60]$, as well as from other validated scales from both the Substance Abuse and Mental Health Services Administration (SAMHSA) 2014 Communities that Care survey instrument and the 2012 Monitoring the Future survey [61]. The 88-item instrument was programmed into the SurveyMonkey software for computer-administered completion during a required freshmen English class at each of the high schools and took an average of 15 min to complete. In addition to demographic information and last grade completed in school, other scales used included the following: traditional and digital media use; attitudes toward social media; drug use risk perceptions; personal and perceived peer reasons to use drugs; drug use social norms; perceived peer drug use; reported peer drug use; self-reported past 30-day drug use; next 30-day drug use intentions; drug use/refusal influences; and self-reported exposure to the LTE program (ie, self-reported frequency of receiving social media messaging and from whom) and receptivity to the LTE program messages (ie, self-reported trust and how much they liked the program messages). The response option format for the drug use intention measure was on a 5-point Likert scale (ranging from strongly agree to strongly disagree) with statements about drug use intentions.

Additionally, we documented posts from a total of 24 (of the 46 total) youth ambassadors across the 3 high schools to social media platforms of their choice during an 8-month period, primarily on Instagram and Snapchat. We measured ambassador social media outreach activity, ambassador followers, type of outreach (ie, post, story, snap), and peer engagement (ie, likes, comments).

\section{Data Collection}

Working with a local liaison at each high school, we scheduled the questionnaires to be first administered before the initiation of LTE youth ambassador training in November 2018 (baseline or wave 1). The required freshmen classes were invited to participate in the survey, which included a total potential sample of 923 freshmen students across the 3 high schools. We surveyed a total of 826 students at baseline ( $89.5 \%$ of the student census) across the 3 high schools during October and early November 2018. We did not record the students' personally identifiable information, as the study design was cross-sectional. The training was then implemented in 6 weekly sessions followed by an ambassador contest to launch LTE. We completed a midline (wave 2) survey in February to March 2019 with a total of 584 students recruited from the same classes as baseline. Finally, we completed the endline (wave 3) survey in June 2019 with a total of 542 students in the same classes. Thus, at wave 3 , we were able to survey $58.7 \%$ (542/923) of all freshmen and $65.6 \%(542 / 826)$ of those surveyed at wave 1 . Ambassadors were not sampled as part of survey data collection. We cannot independently confirm whether lower rates of completed surveys at follow-up were due to student absences on the survey date or refusal to participate.

We also collected social media data from youth ambassador posts using Hootsuite software and captured ambassador posts with the included \#livingtheexample hashtag. Owing to the nature of the Instagram platform, stories are only available for a 24-hour period; in some cases, program staff requested that ambassadors provide screenshots of their posts for documentation purposes.

\section{Data Analysis}

Drug use intentions, LTE exposure, and demographic (age and gender) data from waves 2 and 3 were appended into a single dataset. We first estimated ordinal logistic regression models for each drug use intention variable in wave 3 (ie, sell/distribute illegal drugs, smoke cigarettes, drink beer/wine/hard liquor when parents do not know about it, use marijuana, use lysergic acid diethylamide (LSD)/cocaine/amphetamines or other illegal drugs, use heroin, use synthetic drugs, use any prescription pills without a prescription) to examine the association between LTE exposure and drug use intentions. We assumed that the relationship between each pair of outcome categories was the same, meaning that the coefficients that describe the relationship between strongly agree versus all higher categories of the response are the same as those that agree versus all higher categories and so on.

In a separate set of regressions, we included an interaction term for the study wave to examine whether participants had stronger disagreement with drug use after the intervention was implemented. All regression models controlled for participant's age and gender. All data analysis was conducted in $\mathrm{R}$ version 3.5.3 ( $\mathrm{R}$ Core Team, 2019). All regressions fit model assumptions have been described.

\section{Results}

We recorded LTE social media activity from a total of 24 (of the 46) youth ambassadors. The Instagram story function was the most widely used by ambassadors, with a total of 45 stories, followed by 28 Instagram posts made during the program. The ambassadors had a total of 12,894 followers in their social media networks during the program period. There were 1291 follower likes for posts by ambassadors and 33 comments made by followers, likely a partial representation of engagement. It is worth noting that we cannot confirm that we captured all social media posts created by the ambassadors as some students may not have used the hashtag or provided complete data to the 
coordinator on their posting activity. It should also be noted that, due to the nature of social media platforms, we cannot confirm the identity of individuals in the youth ambassadors' networks who engaged with the posts or how many of them represent unique individuals.
In the outcome surveys, we collected limited demographic information, and $52 \%$ of respondents were female, $55 \%$ were aged 14 years and $45 \%$ were aged 15 years, $96 \%$ were born in the United States, and all were freshmen. The survey focused mainly on substance use attitudes, beliefs, intentions, and behavior. Mean responses to the drug use intention scales for the outcomes of interest are shown in Table 1.

Table 1. Overall mean differences in drug use intentions among all baseline, midline, and endline groups.

\begin{tabular}{|c|c|c|c|c|}
\hline Measures & $\begin{array}{l}\text { Baseline }(\mathrm{n}=835) \\
\text { mean }(\mathrm{SD})\end{array}$ & $\begin{array}{l}\text { Midline }(\mathrm{n}=593) \\
\text { mean }(\mathrm{SD})\end{array}$ & $\begin{array}{l}\text { Endline }(\mathrm{n}=557) \text {, mean } \\
\text { (SD) }\end{array}$ & $P$ value \\
\hline Sell/distribute illegal drugs ${ }^{\mathrm{a}}$ & $3.69(0.68)$ & $3.58(0.82)$ & $3.54(0.83)$ & $<.001$ \\
\hline Smoke cigarettes & $3.72(0.60)$ & $3.67(0.69)$ & $3.57(0.81)$ & $<.001$ \\
\hline $\begin{array}{l}\text { Drink beer, wine, or hard liquor (eg, vodka, whiskey, or gin) } \\
\text { when my parents do not know about it }\end{array}$ & $3.56(0.77)$ & $3.47(0.85)$ & $3.36(0.93)$ & $<.001$ \\
\hline Use marijuana & $3.56(0.81)$ & $3.48(0.88)$ & $3.36(0.99)$ & $<.001$ \\
\hline Use LSD, cocaine, amphetamines, or other illegal drugs & $3.74(0.62)$ & $3.72(0.65)$ & $3.63(0.77)$ & .008 \\
\hline Use heroin & $3.75(0.61)$ & $3.72(0.66)$ & $3.65(0.77)$ & .013 \\
\hline Use synthetic drugs (eg, K2, spice, bath salts) & $3.75(0.60)$ & $3.74(0.64)$ & $3.63(0.77)$ & .002 \\
\hline Use prescription pills without a prescription & $3.71(0.65)$ & $3.66(0.73)$ & $3.59(0.80)$ & .007 \\
\hline
\end{tabular}

${ }^{\mathrm{a}}$ For each of the following questions, please indicate whether you strongly agree $=1$, agree $=2$, neither agree nor disagree $=3$, disagree $=4$, or strongly disagree $=5$.

Next, we estimated ordinal logistic regression models for each of the 30-day substance use intention outcomes of interest (Table 2). In this model, we found a significant positive effect of LTE exposure on all 8 measured drug use intention variables: sell/distribute illegal drugs; smoke cigarettes; drink beer, wine or liquor when my parents do not know about it; use marijuana; use LSD, cocaine, amphetamines, or other illegal drug; use heroin; use synthetic drugs; use any prescription pills without a prescription (all $P<.05$; odds ratios ranging from 2.12 to 3.71 ). We also found that boys were more likely than girls to exhibit reductions in drug use intentions.

Table 2. Logistic regressions of drug use intentions on Living the Example program exposure at wave 3, exponentiated coefficient ( $\mathrm{n}=542$ ).

\begin{tabular}{|c|c|c|c|c|c|c|c|c|}
\hline \multirow[t]{2}{*}{ Measures } & \multicolumn{8}{|c|}{ Self-reported drug use intention, exponentiated coefficient ( $P$ value $)$} \\
\hline & $1^{\mathrm{a}}$ & $2^{\mathrm{b}}$ & $3^{\mathrm{c}}$ & $4^{\mathrm{d}}$ & $5^{\mathrm{e}}$ & $6^{\mathrm{f}}$ & $7^{\mathrm{g}}$ & $8^{\mathrm{h}}$ \\
\hline LTE $^{\mathrm{i}}$ exposure & $2.96(<.003)$ & $3.42(<.001)$ & $2.12(<.007)$ & $2.91(<.003)$ & $3.61(<.001)$ & $3.58(<.001)$ & $3.71(<.001)$ & $3.44(<.001)$ \\
\hline Age (years) & $0.99(.94)$ & $0.85(.33)$ & $1.08(.56)$ & $1.23(.15)$ & $0.94(.73)$ & $0.81(.23)$ & $0.93(.64)$ & $0.98(.90)$ \\
\hline Gender (female; reference) & $2.72(<.006)$ & $2.71(<.007)$ & $1.94(<.009)$ & $2.74(<.006)$ & $3.60(<.001)$ & $3.24(<.003)$ & $3.03(<.004)$ & $2.76(<.006)$ \\
\hline
\end{tabular}

${ }^{\text {a }}$ Sell/distribute illegal drugs.

${ }^{\mathrm{b}}$ Smoke cigarettes.

${ }^{\mathrm{c}}$ Drink beer, wine, or hard liquor (eg, vodka, whiskey, or gin) when my parents do not know about it.

${ }^{\mathrm{d}}$ Use marijuana.

${ }^{\mathrm{e}}$ Use LSD, cocaine, amphetamines, or other illegal drugs.

${ }^{\mathrm{f}}$ Use heroin.

${ }^{\mathrm{g}}$ Use synthetic drugs (eg, K2, spice, bath salts).

${ }^{\mathrm{h}}$ Use any prescription pills without a prescription.

${ }^{\mathrm{i}}$ LTE: Living the Example.

Next, we estimated a separate model that included a survey wave interaction term to examine the hypothesis that substance use intentions declined during the LTE program as a function of exposure to peer-to-peer prevention messages via social media. As hypothesized, we observed reductions in 30-day intentions to use all 8 measured drugs between the second and third follow-up surveys, the period during which the social media messaging component of the LTE program took place (Table 3). 
Table 3. Logistic regressions of drug use intentions on Living the Example program exposure and survey waves 2 to 3, exponentiated coefficient.

\begin{tabular}{lllllllll}
\hline Measures & \multicolumn{2}{l}{ Self-reported drug use intention, exponentiated coefficient $(P$ value $)$} & & & \\
& $1^{\mathrm{a}}$ & $2^{\mathrm{b}}$ & $3^{\mathrm{c}}$ & $4^{\mathrm{d}}$ & $5^{\mathrm{e}}$ & $6^{\mathrm{f}}$ & $7^{\mathrm{g}}$ & $8^{\mathrm{h}}$ \\
\hline LTE & $3.31(<.001)$ & $3.30(<.001)$ & $2.43(<.008)$ & $2.58(<.007)$ & $3.33(<.001)$ & $3.73(<.001)$ & $3.57(<.001)$ & $3.45(<.001)$ \\
Wave 2 (reference) & $1.06(.66)$ & $1.29(.07)$ & $1.16(.24)$ & $1.14(.32)$ & $1.30(.09)$ & $1.21(.21)$ & $1.41(.02)$ & $1.16(.31)$ \\
Age (years) & $1.21(.08)$ & $0.99(.91)$ & $1.15(.17)$ & $1.31(.01)$ & $0.98(.89)$ & $0.98(.85)$ & $1.03(.83)$ & $1.13(.31)$ \\
Gender (female; reference) & $2.35(<.009)$ & $2.00(<.012)$ & $1.48(<.018)$ & $2.15(<.011)$ & $2.42(<.007)$ & $2.43(<.007)$ & $2.16(<.011)$ & $2.11(<.011)$ \\
\hline
\end{tabular}

${ }^{\mathrm{a}}$ Sell/distribute illegal drugs.

${ }^{\mathrm{b}}$ Smoke cigarettes.

${ }^{\mathrm{c}}$ Drink beer, wine, or hard liquor (eg, vodka, whiskey, or gin) when my parents do not know about it.

${ }^{\mathrm{d}}$ Use marijuana.

${ }^{\mathrm{e}}$ Use LSD, cocaine, amphetamines, or other illegal drugs.

${ }^{\mathrm{f}}$ Use heroin.

${ }^{\mathrm{g}}$ Use synthetic drugs (eg, K2, spice, bath salts).

${ }^{\mathrm{h}}$ Use any prescription pills without a prescription.

${ }^{\mathrm{i}}$ LTE: Living the Example.

\section{Discussion}

\section{Principal Findings}

LTE had a positive effect on reducing substance use intentions among high school students. Overall, results of this study were consistent with and indicate a stronger LTE effect in this study compared with the 2016-2017 previous pilot study [42]. LTE appears to offer a protective effect, with exposure to program messages leading to reduced drug use intentions. This approach deserves further development, refinement, and evaluation using rigorous randomized controlled methods that capture detailed dose-response data.

With regard to our hypotheses, first we saw some evidence that ambassadors were successful in reaching their peers. We were able to independently record social media posts for 24 ambassadors who produced LTE messages and shared them with nearly 13,000 followers over a period of 8 months. This demonstrates the feasibility of the LTE model reaching a large number of youths using a peer-to-peer approach at a low cost. Although the LTE program intended to leverage social media platforms that were most widely used by youth participants and their peer networks, some platforms, including Instagram, presented unique challenges for program implementers and evaluators. Instagram stories disappear from a user's profile after 24 hours, introducing barriers for documenting the content, features, and persuasive tactics used by ambassadors. Additionally, some ambassadors had private Instagram profiles, which prevented our documenting their posts. The abbreviated postduration also limits the extent to which the content can be viewed by followers and potentially shared on follower profiles. Regardless, LTE demonstrated significant potential to reach large numbers of peers via social media networks, with some months having over 10,000 followers of ambassadors on Instagram when there were only 14 ambassadors making at least one post during that period.

Second, we found that exposure to LTE is indeed associated with reduced 30-day drug use intentions, confirming our previous pilot study findings [42]. In our first set of regressions, we found that self-reported exposure to LTE was associated with lower use intentions across all 8 measured substances, including widely used drugs such as marijuana and prescription painkillers (opioids). This suggests that LTE is an effective approach that deserves large-scale implementation and evaluation.

Third, we found evidence of a dose-response relationship between LTE exposure and reduced 30-day drug use intentions. There was an effect of exposure to peer-to-peer messaging over time, with youths who self-reported exposure showing reduced use intentions at the wave 3 endline follow-up. Dose-response effects are important evidence for the effectiveness of media interventions, first as they demonstrate a direct relationship between the media stimulus and outcomes of interest and second as they provide evidence for the magnitude of those effects [62]. Optimizing dosage is an important objective for health campaigns [63] and for this research.

\section{Future Research and Limitations}

Future research should use a randomized controlled trial design to compare implementing and nonimplementing schools and examine dose-response effects in detail. A group randomized trial involving sufficient numbers of schools for statistical power purposes assigned both to implement and not implement LTE across a school year would provide confirmatory evidence of the program's effectiveness. Together with detailed measurement of social media activity both through independent monitoring of posting activity at the individual ambassador level and through self-report, a future study such as this could specify the optimal dosage for LTE to produce meaningful prevention effects.

There are some limitations to this study. First, the number of survey respondents declined in wave 2 and 3 follow-ups, but we cannot confirm whether students were not in attendance during survey administration or they did not agree to complete the follow-up surveys. Second, we were only able to independently confirm LTE social media activity for 24 of the 
46 ambassadors. We were unable to track potential posting for some ambassadors due to the omission of program hashtags in posts, due to use of the hashtags but with private Instagram account settings, or due to posting on the Snapchat platform, which does not permit hashtag tracking and is otherwise quite difficult to monitor. Additionally, we cannot quantify how many of the posts we documented, and engagement statistics we captured, represent unique individual users. Consequently, our independent social media data are incomplete. Finally, due to limitations with the social media monitoring, we were not able to statistically analyze the relationship between independent social media metrics and outcomes measured in the surveys.

\section{Conclusions}

Adolescent substance use continues to be a pressing public health threat in the United States, in particular due to the growing availability of lethal drugs, teen social norms shifting to be more favorable of recreational use, and growing perceptions of the relative safety of some substances [2-4]. Digital social networks are major drivers of public perceptions of substance use [7,25,26], calling for novel digital strategies for prevention in this space. LTE offers a promising model for future programming seeking to widely disseminate peer-to-peer prevention messaging via social media to reduce adolescent drug use intentions. By training a relatively small number of youths, there is potential to reach a large audience with authentic, targeted prevention messages, given the widespread use of social networking platforms. Future research should build on the evidence of the effectiveness of LTE by implementing and evaluating the program at a larger scale using randomized controlled methods.

\section{Conflicts of Interest}

None declared.

\section{References}

1. Johnston LD, O'Malley P, Miech R, Bachman J, Schulenberg J. Deep Blue. Ann Arbor: Institute for Social Research, The University of Michigan; 2015. Monitoring the Future national survey results on drug use, 1975-2014: Overview, key findings on adolescent drug use URL: https://tinyurl.com/y76qlqqd [accessed 2020-03-09]

2. Keyes KM, Schulenberg J, O'Malley P, Johnston L, Bachman J, Li G, et al. The social norms of birth cohorts and adolescent marijuana use in the United States, 1976-2007. Addiction 2011 Oct;106(10):1790-1800 [FREE Full text] [doi: 10.1111/j.1360-0443.2011.03485.x] [Medline: 21545669]

3. Substance Abuse and Mental Health Services Administration. Washington, DC: Department of Health and Human Services; 2017. Key Substance Use and Mental Health Indicators in the United States: Results from the 2016 National Survey on Drug Use and Health URL: https://www.samhsa.gov/data/sites/default/files/NSDUH-FFR1-2016/NSDUH-FFR1-2016.htm [accessed 2020-03-09]

4. Johnston LD, Miech R, O'Malley P, Bachman J, Schulenberg J, Patrick M. Deep Blue. Ann Arbor, MI: University of Michigan; 2019. Monitoring the Future national survey results on drug use, 1975-2018: Overview, key findings on adolescent drug use URL: https://tinyurl.com/ycqqoqet [accessed 2020-03-09]

5. Levy S. Youth and the Opioid Epidemic. Pediatrics 2019 Feb;143(2):pii: e20182752 [FREE Full text] [doi: 10.1542/peds.2018-2752] [Medline: 30602544]

6. Committee on Communications, American Academy of Pediatrics, Strasburger VC. Children, adolescents, and advertising. Pediatrics 2006 Dec;118(6):2563-2569. [doi: 10.1542/peds.2006-2698] [Medline: 17142547]

7. Miech RA, Johnston L, O'Malley PM, Bachman JG, Schulenberg J, Patrick ME. Trends in use of marijuana and attitudes toward marijuana among youth before and after decriminalization: the case of California 2007-2013. Int J Drug Policy 2015 Apr;26(4):336-344 [FREE Full text] [doi: 10.1016/j.drugpo.2015.01.009] [Medline: 25662893]

8. Schmidt LA, Jacobs LM, Spetz J. Young people's more permissive views about marijuana: local impact of state laws or national trend? Am J Public Health 2016;106(8):1498-1503. [doi: 10.2105/ajph.2016.303153]

9. Johnston LD, O'Malley P, Bachman J, Schulenberg J, Patrick M. Education Resources Information Center. Ann Arbor, MI: Institute for Social Research, The University of Michigan; 2017. Monitoring the Future National Survey Results on Drug Use, 1975-2016: Overview, Key Findings on Adolescent Drug Use URL: https://eric.ed.gov/?id=ED578534 [accessed 2020-03-09]

10. Curtin SC, Tejada-Vera B, Warmer M. Drug overdose deaths among adolescents aged 15-19 in the United States: $1999-2015$. NCHS Data Brief 2017 Aug(282):1-8 [FREE Full text] [Medline: 29155681]

11. Miller T, Hendrie D. Substance Abuse and Mental Health Services Administration. 2008. Substance Abuse Prevention Dollars and Cents: A Cost-Benefit Analysis URL: https://www.samhsa.gov/sites/default/files/cost-benefits-prevention.pdf [accessed 2020-03-09]

12. Evans WD, Blitstein J, Hersey JC, Renaud J, Yaroch AL. Systematic review of public health branding. J Health Commun 2008 Dec;13(8):721-741. [doi: 10.1080/10810730802487364] [Medline: 19051110]

13. Patrick ME, Schulenberg JE, O'Malley PM, Johnston LD, Bachman JG. Adolescents' reported reasons for alcohol and marijuana use as predictors of substance use and problems in adulthood. J Stud Alcohol Drugs 2011 Jan;72(1):106-116 [FREE Full text] [doi: 10.15288/jsad.2011.72.106] [Medline: 21138717] 
14. Lisdahl KM, Gilbart ER, Wright NE, Shollenbarger S. Dare to delay? The impacts of adolescent alcohol and marijuana use onset on cognition, brain structure, and function. Front Psychiatry 2013;4:53 [FREE Full text] [doi: 10.3389/fpsyt.2013.00053] [Medline: 23847550 ]

15. Centers for Disease Control and Prevention. Atlanta: US Department of Health and Human Services; 2014. Best Practices for Comprehensive Tobacco Control Programs URL: https://www.cdc.gov/tobacco/stateandcommunity/best practices/pdfs/ 2014/comprehensive.pdf [accessed 2020-03-09]

16. Jager G, Block RI, Luijten M, Ramsey NF. Cannabis use and memory brain function in adolescent boys: a cross-sectional multicenter functional magnetic resonance imaging study. J Am Acad Child Adolesc Psychiatry 2010 Jun;49(6):561-72, 572.e1 [FREE Full text] [doi: 10.1016/j.jaac.2010.02.001] [Medline: 20494266]

17. Medina KL, Schweinsburg AD, Cohen-Zion M, Nagel BJ, Tapert SF. Effects of alcohol and combined marijuana and alcohol use during adolescence on hippocampal volume and asymmetry. Neurotoxicol Teratol 2007;29(1):141-152 [FREE Full text] [doi: 10.1016/j.ntt.2006.10.010] [Medline: 17169528]

18. McGuinness TM. Update on marijuana. J Psychosoc Nurs Ment Health Serv 2009 Oct;47(10):19-22. [doi: 10.3928/02793695-20090902-03] [Medline: 19835316]

19. Pedersen ER, Miles JN, Ewing BA, Shih RA, Tucker JS, D'Amico EJ. A longitudinal examination of alcohol, marijuana, and cigarette perceived norms among middle school adolescents. Drug Alcohol Depend 2013 Dec 1;133(2):647-653 [FREE Full text] [doi: 10.1016/j.drugalcdep.2013.08.008] [Medline: 24012070]

20. Walker DD, Neighbors C, Rodriguez LM, Stephens RS, Roffman RA. Social norms and self-efficacy among heavy using adolescent marijuana smokers. Psychol Addict Behav 2011 Dec;25(4):727-732 [FREE Full text] [doi: 10.1037/a0024958] [Medline: 21842969]

21. Friese B, Grube JW. Legalization of medical marijuana and marijuana use among youths. Drugs (Abingdon Engl) 2013 Feb 1;20(1):33-39 [FREE Full text] [doi: 10.3109/09687637.2012.713408] [Medline: 23641127]

22. Mason WA, Hanson K, Fleming CB, Ringle JL, Haggerty KP. Washington State recreational marijuana legalization: parent and adolescent perceptions, knowledge, and discussions in a sample of low-income families. Subst Use Misuse 2015 Apr;50(5):541-545 [FREE Full text] [doi: 10.3109/10826084.2014.952447] [Medline: 25671633]

23. NIDA for Teens. Bethesda, MD: NIDA Prescription Pain Medications (Opioids) URL: https://teens.drugabuse.gov/drug-facts/ prescription-pain-medications-opioids [accessed 2020-01-31]

24. Jones CM, Einstein EB, Compton WM. Changes in synthetic opioid involvement in drug overdose deaths in the United States, 2010-2016. J Am Med Assoc 2018 May 1;319(17):1819-1821 [FREE Full text] [doi: 10.1001/jama.2018.2844] [Medline: 29715347]

25. Cerdá M, Wall M, Keyes KM, Galea S, Hasin D. Medical marijuana laws in 50 states: investigating the relationship between state legalization of medical marijuana and marijuana use, abuse and dependence. Drug Alcohol Depend 2012 Jan 1;120(1-3):22-27 [FREE Full text] [doi: 10.1016/j.drugalcdep.2011.06.011] [Medline: 22099393]

26. Schuermeyer J, Salomonsen-Sautel S, Price RK, Balan S, Thurstone C, Min S, et al. Temporal trends in marijuana attitudes, availability and use in Colorado compared to non-medical marijuana states: 2003-11. Drug Alcohol Depend 2014 Jul 1;140:145-155 [FREE Full text] [doi: 10.1016/j.drugalcdep.2014.04.016] [Medline: 24837585]

27. Greene K, Catona D, Elek E, Magsamen-Conrad K, Banerjee SC, Hecht ML. Improving prevention curricula: lessons learned through formative research on the youth message development curriculum. J Health Commun 2016 Oct;21(10):1071-1078 [FREE Full text] [doi: 10.1080/10810730.2016.1222029] [Medline: 27684111]

28. Slater MD, Kelly KJ, Lawrence FR, Stanley LR, Comello ML. Assessing media campaigns linking marijuana non-use with autonomy and aspirations: 'Be Under Your Own Influence' and ONDCP's 'Above the Influence'. Prev Sci 2011 Mar;12(1):12-22 [FREE Full text] [doi: 10.1007/s11121-010-0194-1] [Medline: 21271357]

29. Carpenter CS, Pechmann C. Exposure to the above the influence antidrug advertisements and adolescent marijuana use in the United States, 2006-2008. Am J Public Health 2011 May;101(5):948-954. [doi: 10.2105/ajph.2010.300040]

30. Evans WD, Holtz K, White T, Snider J. Effects of the above the influence brand on adolescent drug use prevention normative beliefs. J Health Commun 2014;19(6):721-737. [doi: 10.1080/10810730.2013.837559] [Medline: 24499473]

31. Hecht ML, Lee JK. Branding through cultural grounding: The keepin' it REAL curriculum. In: Evans DW, Hastings G, editors. Public Health Branding: Applying Marketing for Social Change. London: Oxford University Press; 2008.

32. Evans WD, Price S, Blahut S. Evaluating the truth brand. J Health Commun 2005 Mar;10(2):181-192. [doi: 10.1080/10810730590915137] [Medline: 15804907]

33. Evans WD, Taruberekera N, Longfield K, Snider J. Brand equity and willingness to pay for condoms in Zimbabwe. Reprod Health 2011 Oct 26;8:29 [FREE Full text] [doi: 10.1186/1742-4755-8-29] [Medline: 22029874]

34. Mentor Foundation USA. 2019 Apr 15. 'Shatter the Myths' Youth Rally at Glen Burnie High School URL: http:/ Imentorinternational.org/usa\%20on\%20May\%2029 [accessed 2020-01-30]

35. Substance Abuse and Mental Health Services Administration. Washington, DC: Department of Health and Human Services Results from the 2011 National Survey on Drug Use and Health: Summary of National Findings URL: https://tinyurl.com/ ycbn2a9q [accessed 2020-03-09]

36. NIDA for Teens. 2014. Marijuana URL: http://teens.drugabuse.gov/drug-facts/marijuana [accessed 2019-06-02] 
37. Jacobus J, Squeglia LM, Sorg SF, Nguyen-Louie TT, Tapert SF. Cortical thickness and neurocognition in adolescent marijuana and alcohol users following 28 days of monitored abstinence. J Stud Alcohol Drugs 2014 Sep;75(5):729-743 [FREE Full text] [doi: 10.15288/jsad.2014.75.729] [Medline: 25208190]

38. Evans WD, Rath JM, Hair EC, Snider JW, Pitzer L, Greenberg M, et al. Effects of the truth FinishIt brand on tobacco outcomes. Prev Med Rep 2018 Mar;9:6-11 [FREE Full text] [doi: 10.1016/j.pmedr.2017.11.008] [Medline: 29276667]

39. Calkins T. The challenge of branding. In: Calkins T, Tybout A, editors. Kellogg on Branding. New York: John Wiley and Sons; 2005.

40. Shek DT, Dou D, Zhu X, Chai W. Positive youth development: current perspectives. Adolesc Health Med Ther 2019;10:131-141 [FREE Full text] [doi: 10.2147/AHMT.S179946] [Medline: $\underline{\text { 31572041] }}$

41. Evans WD, Andrade EL, Barrett ND, Cleary SD, Snider J, Edberg M. The mediating effect of Adelante brand equity on Latino immigrant positive youth development outcomes. J Health Commun 2018;23(7):606-613 [FREE Full text] [doi: 10.1080/10810730.2018.1496205] [Medline: $\underline{30138045]}$

42. Evans W, Andrade E, Goldmeer S, Smith M, Snider J, Girardo G. The living the example social media substance use prevention program: a pilot evaluation. JMIR Ment Health 2017 Jun 27;4(2):e24 [FREE Full text] [doi: 10.2196/mental.7839] [Medline: 28655704]

43. Pew Research Center. 2014 Apr 2. Section 2: Views of Marijuana - Legalization, Decriminalization, Concerns URL: http:/ /www.people-press.org/2014/04/02/section-2-views-of-marijuana-legalization-decriminalization-concerns/ [accessed 2020-01-31]

44. Pew Research Center. 2014 Apr 2. Feds May Be Rethinking the Drug War, but States Have Been Leading the Way URL: http://www.pewresearch.org/fact-tank/2014/04/02/feds-may-be-rethinking-the-drug-war-but-states-have-been-leading-the-way/ [accessed 2019-05-26]

45. Neighbors C, Foster DW, Walker DD, Kilmer JR, Lee CM. Social identity as a moderator of the association between perceived norms and marijuana use. J Stud Alcohol Drugs 2013 May;74(3):479-483 [FREE Full text] [doi: 10.15288/jsad.2013.74.479] [Medline: 23490578]

46. Above the Influence. Bethesda, MD: NIDA Drug Facts URL: https://abovetheinfluence.com/drug-facts/ [accessed 2020-01-31]

47. Elliott S. The New York Times. 2013 Jun 15. Antidrug Campaign, Lacking Federal Funds, Turns to Social Media URL: http://www.nytimes.com/2013/07/16/business/media/antidrug-campaign-lacking-federal-funds-turns-to-social-media.html [accessed 2019-01-30]

48. Rothman AJ, Bartels RD, Wlaschin J, Salovey P. The strategic use of gain- and loss-framed messages to promote healthy behavior: how theory can inform practice. J Commun 2006;56(1):S202-S220. [doi: 10.1111/j.1460-2466.2006.00290.x]

49. Rothman AJ, Salovey P, Antone C, Keough K, Martin CD. The influence of message framing on intentions to perform health behaviors. J Exp Soc Psychol 1993;29(5):408-433. [doi: 10.1006/jesp.1993.1019]

50. O'Keefe DJ, Jensen JD. The relative persuasiveness of gain-framed and loss-framed messages for encouraging disease prevention behaviors: a meta-analytic review. J Health Commun 2007;12(7):623-644. [doi: 10.1080/10810730701615198] [Medline: 17934940]

51. Huhman ME, Potter LD, Nolin MJ, Piesse A, Judkins DR, Banspach SW, et al. The Influence of the VERB campaign on children's physical activity in 2002 to 2006. Am J Public Health 2010 Apr;100(4):638-645. [doi: 10.2105/AJPH.2008.142968] [Medline: 19608963]

52. Farrelly MC, Davis KC, Haviland ML, Messeri P, Healton CG. Evidence of a dose—response relationship between 'Truth' antismoking ads and youth smoking prevalence. Am J Pub Health 2005;95(3):425-431. [doi: 10.2105/ajph.2004.049692]

53. Evans WD, Price S, Blahut S, Hersey J, Niederdeppe J, Ray S. Social imagery, tobacco independence, and the TruthSM campaign. J Health Commun 2004 Sep;9(5):425-441. [doi: 10.1080/1081073049050413]

54. Mays D, Niaura RS, Evans WD, Hammond D, Luta G, Tercyak KP. Cigarette packaging and health warnings: the impact of plain packaging and message framing on young smokers. Tob Control 2015 Mar;24(e1):e87-e92 [FREE Full text] [doi: 10.1136/tobaccocontrol-2013-051234] [Medline: 24420310]

55. Evans WD, Davis KC, Umanzor C, Patel K, Khan M. Evaluation of sexual communication message strategies. Reprod Health 2011 May 20;8:15 [FREE Full text] [doi: 10.1186/1742-4755-8-15] [Medline: 21599875]

56. McGuire W. Theoretical foundations of campaigns. In: Rice R, Atkin CK, editors. Public Communication Campaigns. Thousand Oaks, CA: Sage Publications; 1981.

57. Tversky A, Kahneman D. The framing of decisions and the psychology of choice. Science 1981 Jan 30;211(4481):453-458. [doi: $10.1126 /$ science.7455683] [Medline: 7455683 ]

58. Gallagher KM, Updegraff JA. Health message framing effects on attitudes, intentions, and behavior: a meta-analytic review. Ann Behav Med 2012 Feb;43(1):101-116. [doi: 10.1007/s12160-011-9308-7] [Medline: 21993844]

59. Evans WD. Branding social and health behavior: An education and research agenda. In: Evans WD, editor. Psychology of Branding. Hauppauge, NY: Nova Science Publishers; 2013:133-148.

60. Evans W, Rath J, Pitzer L, Hair E, Snider J, Cantrell J, et al. Design and feasibility testing of the truth FinishIt tobacco countermarketing brand equity scale. J Health Commun 2016 Jul;21(7):800-808. [doi: 10.1080/10810730.2016.1157658] [Medline: 27315354] 
61. National Institute on Drug Abuse. Monitoring the Future URL: https://www.drugabuse.gov/related-topics/trends-statistics/ monitoring-future [accessed 2020-01-30]

62. Davis KC, Alexander RL, Shafer P, Mann N, Malarcher A, Zhang L. The dose-response relationship between tobacco education advertising and calls to Quitlines in the United States, March-June, 2012. Prev Chronic Dis 2015 Nov 5;12:E191 [FREE Full text] [doi: 10.5888/pcd12.150157] [Medline: 26542143]

63. Abroms LC, Ahuja M, Kodl Y, Thaweethai L, Sims J, Winickoff JP, et al. Text2Quit: results from a pilot test of a personalized, interactive mobile health smoking cessation program. J Health Commun 2012;17(Suppl 1):44-53 [FREE Full text] [doi: 10.1080/10810730.2011.649159] [Medline: 22548598]

\author{
Abbreviations \\ GW: George Washington \\ LSD: lysergic acid diethylamide \\ LTE: Living the Example \\ NIDA: National Institute on Drug Abuse \\ PYD: Positive Youth Development \\ QED: quasi-experimental design \\ SAMHSA: Substance Abuse and Mental Health Services Administration \\ STM: Shatter the Myths
}

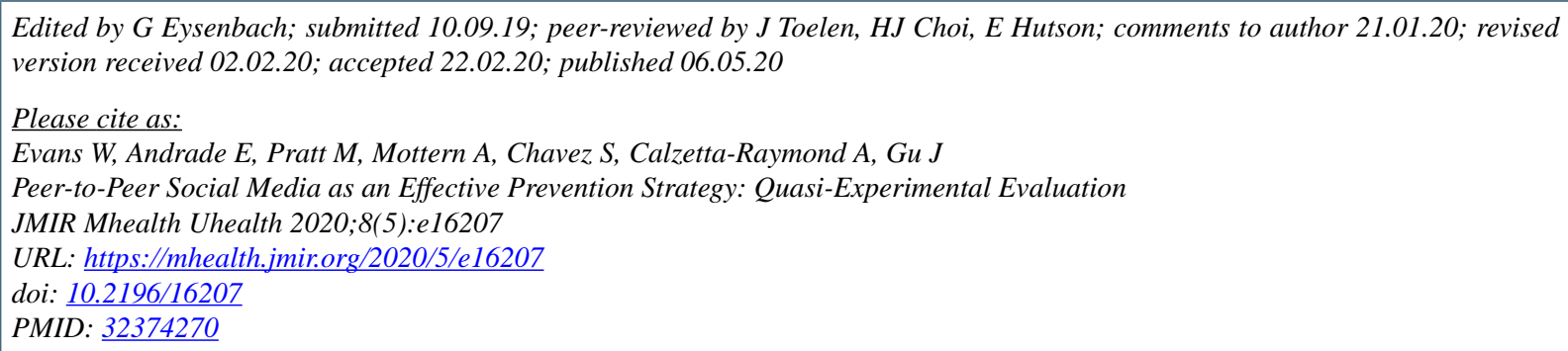

(C) William Evans, Elizabeth Andrade, Michaela Pratt, Alexandra Mottern, Sergio Chavez, Anthony Calzetta-Raymond, Jiayan Gu. Originally published in JMIR mHealth and uHealth (http://mhealth.jmir.org), 06.05.2020. This is an open-access article distributed under the terms of the Creative Commons Attribution License (https://creativecommons.org/licenses/by/4.0/), which permits unrestricted use, distribution, and reproduction in any medium, provided the original work, first published in JMIR mHealth and uHealth, is properly cited. The complete bibliographic information, a link to the original publication on http://mhealth.jmir.org/, as well as this copyright and license information must be included. 